\title{
Interatividade nas culturas da infância: aproxima- ções, amizade e conflitos entre bebês
}

\section{Resumo}

Ana Cristina Coll Delgado

Universidade Federal de Pelotas

Rogério Costa Würdig

Patrícia Pereira Cava

Universidade Federal de Pelotas

artigo tem como objetivo analisar a interatividade entre bebês em uma escola infantil municipal, com ênfase nas suas aproximações, relações de amizade e conflitos. Trata-se de uma investigação qualitativa, inspirada na etnografia com crianças, que utilizou como instrumentos para coleta de dados a observação com notas de campo e filmagens. $\bigcirc$ quadro teórico sustenta-se em autores que reconhecem os bebês como capazes de compartilhar experiências entre si, especialmente nas formas como se aproximam, criam laços de amizade e resolvem conflitos. Compreendemos a interatividade como construída social e culturalmente, pois, tratar da amizade e dos conflitos, apenas, no âmbito de uma disposição interna seria um contrassenso. A interpretação dos dados confrontou-nos com impressões, vídeos e notas de campo na produção de sentidos. Encontramos certa frequência nos agrupamentos intragênero e o estatuło da popularidade entre alguns bebês. Outro ponto a destacar é que as interações não se mantinham estáveis, provavelmente uma estratégia para manter contatos mais alargados e obter aceitação e participação no grupo.

Palavras-chave: Bebês. Amizades. Conflitos.

\section{Interactivity in childhood cultures: approaches, friendship and con- flicts among babies}

\section{Abstract}

The article aims to analyze the interactivity between babies in a municipal nursery school, with emphasis on their approximations, relationships of friendship and conflicts. It is a qualitative investigation, inspired by the ethnography with children that used as instruments for data collection observation with field notes and filming. The theoretical framework is based on authors who recognize babies as capable of sharing experiences with one another, especially in the ways they approach, create bonds of friendship, and resolve conflicts. We understand interactivity as socially and culturally constructed for dealing with friendship and conflict only within the framework of an 
internal disposition would be counter-intuitive. The interpretation of the data confronted us with impressions, videos and field notes in the production of meanings. We found a certain frequency in intra-gender groupings and the status of popularity among some babies. Another point to note is that the interactions were not stable, probably a strategy to maintain wider contacts and gain acceptance and participation in the group.

Keywords: Babies. Friendships. Conflicts.

\section{Interactividad en las culturas de la infancia: aproximaciones, amistad y conflictos entre bebés}

\section{Resumen}

El artículo discute resultados de una investigación cualitativa con bebés en el contexto de una escuela infantil pública, con énfasis en la interactividad, un marco de las culturas de la infancia, comprendiendo amistades y conflictos entre bebés. Los instrumentos metódicos utilizados fueron observación con notas de campo y filmografías. El cuadro teórico se sustenta en autores que reconocen a los bebés como capaces de compartir experiencias entre ellos, especialmente en las formas como se aproximan, crean lazos de amistad y resuelven problemas. Comprendemos la interactividad como construida social y culturalmente, pues se trata de la amistad y de los conflictos en el ámbito de una disposición interna sería un contrasentido. La interpretación de los datos nos enfrenta a las impresiones, vídeos y notas de campo en la producción de sentido. Nos encontramos cierta frecuencia en grupos intragênero y el estatuto de popularidad entre algunos bebés. Otro punto a destacar es que las interacciones no se mantenían estables, probablemente una estrategia para mantener contactos más largos y obtener aceptación e participación en el grupo.

Palabras clave: Bebés. Amistades. Conflictos.

\section{Para começar: interatividade, culturas da infância e estudos da criança}

'Oferecendo comida para o amigo'

É hora do almoço. Davi está almoçando sozinho, enquanto Mikael, que espera ser servido, o observa comer. Olha atentamente para o prato de Davi e faz movimentos com a boca como se estivesse mastigando, porém, não tem nada na boca. Ao mesmo tempo em que Mikael faz estes movimentos com a boca, 'Davi mastiga, olhando para a filmadora e imediatamente tira da boca um grão de arroz, levando-o até a boca de Mikael'. Este abre a boca, aceitando o 
alimento, mas Davi tira a mão de perto da boca do colega 'antes que este consiga pegá-lo'. Mikael fica observando a mão de Davi, enquanto este olha para a mão e percebe que o grão de arroz está entre seus dedos, mas segue almoçando. Mikael, percebendo que o grão está na mão de Davi, tenta pegá-lo, mas Davi esconde a mão, porém Mikael consegue pegar e comer. Davi põe a colher com comida na boca e a retira, sobram alguns grãos na colher, então ele olha e pega cuidadosamente com a ponta dos dedos um grão de feijão e estica seu braço em direção a boca do amigo, mas este não vê, pois está olhando para o outro lado, onde estão as professoras. Nesse momento uma das professoras percebe esta ação e, em um tom de voz alto, fala:'Davi não precisa dar para o Mikael, agora a tia dá'. A outra professora, ainda sobre a ação de Davi, diz:'dá pra ti que já tá de bom tamanho'. A professora que chamou a atenção de Davi na primeira vez complementa: 'se tu conseguir comer já tá bom'. Davi segue comendo e Mikael está olhando em direção às professoras que estão distribuindo, aos poucos, as refeições para os bebês. [...] Mikael continua esperando a comida e esfrega muito os olhos, várias vezes, com uma expressão de sono, cansaço (BERÇÁRIO 1, 2013).

Iniciamos o artigo com um episódio protagonizado por dois bebês, em que um deles oferece alimento ao amigo ao perceber que este necessita de ajuda, ainda que suas cadeirinhas estivessem em posição horizontal. A sequência poderia ser diferente, pois esse indício de aproximação e amizade possivelmente avançaria, não fosse a interrupção das professoras, limitadas pelas rotinas de alimentação da escola infantil que, geralmente, não favorece que bebês ajudem uns aos outros. Partindo desse episódio, nossa intenção é analisar os movimentos de aproximação, as amizades e os conflitos entre bebês, aqui compreendidos como manifestações da interatividade, um traço das culturas da infância' identificado por Sarmento (2004) e Carpenter (2010). Para a pesquisadora canadense, as crianças utilizam "as interações face a face nas suas trocas interpessoais". Assim, um bebê ou uma criança bem pequena, "[...] para entrar num grupo de desconhecidos, se colocará em atitude de pesquisa das outras crianças e tentará estabelecer contato com aquelas com as quais mais se assemelha" (CARPENTER, 2010, p. 49).

Não encontramos ampla literatura dedicada ao tema da amizade e dos conflitos entre bebês, aliás, parece que paira uma suspeita de que bebês sejam realmente competentes para estabelecer laços de amizade com seus 
coetâneos. Fonsagrive (2004) reflete sobre a amizade entre bebês, com notas de campo bastante elucidativas. A autora relata que, a partir de um debate com Françoise Dolto, ocorrido nos anos 1980, ela escutou que, desde bebês, as crianças constroem relações de amizade e inimizades seletivas.

Apostamos que, para que as aproximações se fortaleçam em relações de amizade, é preciso que adultos potencializem e favoreçam a interatividade entre bebês. Além disso, precisamos desconstruir a ideia de que conflitos, exclusões e disputas não fazem parte da construção dos laços de amizade. Estas considerações iniciais reafirmam a relevância do objeto, pois, mesmo nos Estudos da Criança, são recentes as investigações com bebês, ainda que esse campo, segundo Sarmento (2013), possua um caráter de resistência frente aos processos de dominação que ocultam a agência da criança, que não é o adulto imperfeito e imaturo, mas o Outro do adulto. Sobre a agência das crianças, os Estudos da Criança as compreendem como produtoras de culturas e tal produção indica sua potência, pois elas também contribuem para a produção das sociedades adultas (TREVISAN, 2007, 2016; CORSARO, 2010, 2011 ; SARMENTO, 2004, 201 3; BROUGÈRE, 2010, entre outros).

Principalmente pelo estudo das culturas da infância, surgem metodologias de investigação como a etnografia, que tem contribuído para conhecermos as complexidades dos mundos das crianças. Contudo, Ferreira e Nunes (2014) alertam para a baixa incidência de estudos com crianças de zero a três anos. Desse modo, nosso diálogo será pautado principalmente por autores dos Estudos da Criança, pois eles contribuem para pensarmos os bebês como potentes para estabelecer relações de aproximação, amizade e de resolver conflitos entre si.

Os Estudos da Criança reconhecem que a psicologia do desenvolvimento acumulou pesquisas sobre bebês (desde os bebês de colo, pois comumente são considerados bebês os seres humanos de até dois anos)², as quais se dedicaram, principalmente, aos bebês e crianças pequenas europeus, americanos, brancos, de classe média, cujos resultados têm sido universalizados e naturalizados (GOTTLIEB, 2013) .

$\bigcirc$ reconhecimento de que bebês são atores, ainda que utilizem modos exóticos de comunicação (GOTLLEB, 2009), ou estudos sobre como eles adquirem e reconstroem a cultura em que estão inseridos (ROGOFF, 2005) estão mais presentes entre antropólogos da infância ou pesquisadores da 
psicologia cultural. Para Gottlieb (2009) e Rogoff (2005), a representação ocidental de um bebê não é partilhada por todas as culturas. Um exemplo brasileiro são as representações dos bebês como a reencarnação de um ancestral em tribos indígenas (COHN, 2005). Nesses contextos culturais, os bebês são empoderados pelos adultos, pela capacidade de manter contato com o mundo dos mortos e do invisível. Rogoff (2005) evidencia que as sociedades ocidentais ainda não romperam com crenças de que bebês devem passar por uma evolução social e cultural progressiva que culminará na capacidade de andar e falar. Um padrão alternativo para a autora envolve a integração dos bebês nas atividades cotidianas de suas comunidades, mediante observação e participação em atividades socioculturais, sem que haja uma universalidade na correspondência idade-aprendizagem - o que ela observou em tribos africanas pelo uso de materiais pontiagudos ou do fogo por bebês, no convívio com outros grupos geracionais. $\bigcirc$ que para nós parece impossível, bebês manuseando facas e outros instrumentos cortantes, Rogoff (2005) encontrou em suas pesquisas, afirmando que os gestos, os olhares e a entonação são também indicadores nas relações entre bebês e adultos.

Nesse sentido, apostamos nos encontros entre bebês e almejamos 148 contribuir com outras compreensões sobre os seres humanos de pouca idade, pois os bebês aprendem entre si, como também podem ensinar as gerações mais velhas (ROGOFF, 2005; GOTTLIEB, 2009, 201 3; BROUGÉRE, ULMANN, 2012 ). Como refere Brougère, o conceito de aprendizagem ainda é pouco utilizado para evocar o que as crianças ensinam umas às outras, assim como estamos longe de aceitar a ideia de que uma criança possa ensinar alguma coisa a um adulto (BROUGÉRE; ULMANN, 2012).

Retomando o episódio "oferecendo comida para o amigo", filmado em uma escola infantil pública, em uma turma de berçário, com bebês entre cinco e 24 meses, a maioria convivendo na escola por mais de seis horas, uma condição social contemporânea das vidas dos bebês brasileiros e que imprime a eles inúmeras restrições quanto aos seus direitos de expressão, de aprender e compartilhar experiências com seus pares.

Willian Corsaro (2010) define a cultura de pares como um conjunto de atividades ou de rotinas, de artefatos, de valores e de interesses que as crianças produzem e partilham com seus pares. 
Cada vez mais bebês passam longas horas das suas vidas em creches e escolas infantis e, embora a convivência com outros bebês e adultos qualificados para seu cuidado e educação seja um direito garantido na Constituição Brasileira, decorrente de lutas e movimentos sociais, algumas condições causam impacto nas suas vidas, como o confinamento em salas de referência com espaços restritos para movimentos e deslocamentos corporais, com os limites da autonomia de ser e estar criança pequena com suas singularidades, o que também tem implicações nos modos de administração simbólica da pequena infância (SARMENTO, 2004). Pensamos que refletir sobre a interatividade poderá contribuir com a formação inicial e continuada de professoras de educação infantil; afinal, os bebês merecem o prazer de encontrar e interagir com seus parceiros, o que é fundamental "[...] para suportarem uma coletividade regida por regras muito restritas [...]" (FONSAGRIVE, 2004, p. 71). Ainda é presente nas creches, a intenção de formatar a pequena infância para o "ofício de aluno" (SARMENTO, 2011 ).

Conforme estudos de Neyrand (2000), desde a história das primeiras creches, tem predominado a inculcação precoce de adaptação ao funcionamento e interiorização das normas sociais. Assim, a inserção dos bebês na escola, para fora da díade mãe - criança causou o que o autor denomina bebelatria (idolatria dos bebês), que despontou nos anos 1980, no sentido de pré-formar o bebê para desenvolver suas capacidades. Mas foi bem antes, no final da Segunda Guerra Mundial, que se fortaleceu o reconhecimento da vida afetiva do bebê, longe da imagem de um tubo digestivo, como acreditava a medicina de outrora.

Portanto, os saberes sobre a pequena infância, oriundos de diferentes disciplinas dos Estudos da Criança, têm contribuído para reflexões no século XXI sobre a educação e cuidado das crianças de até três anos, cada vez mais institucionalizadas. Considerando as metas do PNE, de que, até 2020, teremos $50 \%$ de bebês e crianças pequenas frequentando creches, justificam-se estudos e pesquisas com esses grupos de idade e que apostem na sua agência.

Cabe esclarecer que, quando falamos de bebês, são eles - meninas e meninos - que estão vivendo no presente a experiência da infância, que têm singularidades que os diferenciam dos adultos, especialmente nas formas como se aproximam como criam laços de amizade entre si e de como esses laços passam por inúmeros conflitos e formas originais de resolução dos mesmos. 
Ressaltamos, com base em Sarmento (2013), que a criança, desde bebê, está imersa em cultura, produz visões do mundo e partilha representações da realidade com outras crianças e adultos. Reivindicar esses aspectos para a compreensão das culturas infantis é lembrar que as crianças sempre foram responsáveis pela integração cultural das demais crianças em grande parte da história humana (ROGOFF, 2005; GOTTLEB, 2009, 2013). A construção do sentimento de pertencimento, de ser aceito ou excluído num grupo, indica que bebês são competentes para estabelecer trocas e aprendizagens sociais e afetivas, não somente com os adultos, mas também com seus coetâneos. Isso apresenta regras, normas, valores e crenças nem sempre compreendidos pelos adultos encarregados do seu cuidado e educação, provavelmente porque há pouco espaço para esses estudos nos cursos de formação de professoras / es. Considerando estas primeiras reflexões, apresentamos, na próxima seção, nossos itinerários metodológicos.

\section{Itinerários metodológicos}

trabalho teve como questão central compreender as relações e culturas dos bebês e crianças bem pequenas entre si e as relações de cuidado e educação com os adultos.

Entretanto, discutimos no artigo um recorte das dimensões de análise, que objetiva analisar a interatividade entre bebês, com ênfase nas aproximações, amizade e conflitos.

Caracterizamos a pesquisa como de abordagem qualitativa, inspirada na etnografia com crianças (GRAUE; WALSH, 2003). Embora essa abordagem não tenha hipóteses e caminhos rígidos, é preciso ter problemas e indagações, os quais foram anunciados na elaboração do projeto e na opção pelo quadro teórico - metodológico.

A geração dos dados foi iniciada em abril de 2013 e finalizada em novembro de 2014, com algumas interrupções decorrentes das férias da Escola Infantil ou da Universidade. $\bigcirc$ contexto em que se deu é o de uma Escola Infantil Municipal (EMEI), localizada em um bairro popular de uma cidade ao sul do Brasil, conhecido como o "bairro cidade" por ser o maior e dividido em sub-bairros.

A EMEI possui infraestrutura precária, com salas pequenas, poucos recursos materiais, brinquedos em mal estado de conservação e ausência 
de banheiros e fraldários nas salas dos berçários. Também não há salas de convivência para professoras/es e para o acolhimento dos familiares das crianças. $\bigcirc$ pátio externo é amplo, com gramado e uma pracinha, contendo brinquedos de madeira com necessidade de manutenção. No entorno, há uma área verde extensa, porém não vimos professoras e crianças usufruindo desse espaço externo à escola durante o percurso da pesquisa. Salientamos, ainda, os problemas com fiação que causaram a interdição da EMEl pelo corpo de bombeiros em abril de 2014 . Como o refeitório é o maior espaço interno, foi dividido para atender crianças e guardar materiais quando houve a interdição da EMEI, desde o ano de 2014 até o primeiro semestre de 2015, quando foram discutidos os resultados das análises com professoras e auxiliares que participaram da pesquisa.

As autorizações dos familiares para que bebês pudessem participar da investigação foram recolhidas em, aproximadamente, duas semanas. Após a obtenção do consentimento, informado pelos familiares, professoras e auxiliares, iniciamos as primeiras observações do berçário e maternal em junho de $2013^{4}$.

Consideramos válido ressaltar que, no início de 2014, novos bebês entraram para a turma do berçário, assim como as professoras e auxiliares também trocaram de turmas, uma situação frequente nas EMEls. Portanto, as aproximações, os acordos e negociações ocorreram durante todo o percurso de investigação. O berçário I, no ano de 2013 , tinha nove crianças: seis meninos e três meninas entre cinco e 12 meses, duas professoras e duas auxiliares. Durante parte do ano de 2014 , seguimos com observações da turma do berçário, agora berçário II, com 17 crianças: oito meninas e nove meninos, entre 10 e 24 meses; três professoras e duas auxiliares.

Citando Denzin (1978), o trabalho fundamentou-se na triangulação dos dados, dos pesquisadores e das teorias.

autor entende que a triangulação combina diferentes formas de análise, o que pode suceder por intermédio da geração dos dados (diversas fontes), dos investigadores (grupo com mais de um pesquisador), da teoria (múltiplas perspectivas ou teorias) e da metodologia (variados métodos) ${ }^{5}$. $\bigcirc$ grupo de pesquisa discutiu e redefiniu os rumos do processo de investigação, realizou amplo debate das transcrições e diários de campo, o que possibilitou a definição das suas principais dimensões de análise. 
Os instrumentos empregados para coleta de dados foram: observação com notas de campo, filmagens e algumas fotografias do cotidiano do berçário, além das rodas de conversa com as profissionais sobre as filmagens. Inicialmente, realizamos observações com notas de campo no período de junho a outubro de 2013 . Somente no mês de novembro do mesmo ano, iniciamos as filmagens, com término em junho de 2014. A escolha de iniciar pelas observações e notas de campo se deu pelo fato de considerarmos necessário estabelecer, aos poucos, uma relação de aproximação e confiança com bebês, professoras e auxiliares para, posteriormente, iniciarmos as filmagens. As observações e filmagens geralmente eram realizadas duas vezes na semana, em dias alternados previamente agendados com as professoras e auxiliares. Decidimos filmar com a câmera nas mãos, tendo liberdade e mais agilidade para deslocamentos nos espaços onde se encontravam as crianças.

Nesses itinerários de pesquisa, a equipe passou a se reunir, semanalmente, para assistir aos vídeos e analisá-los. Após seis horas, 56 minutos e 44 segundos de filmagens, passamos ao recorte dos dados gerados, ação que permitiu uma análise mais atenta e qualificada das filmagens. $O$ grupo elegeu duas grandes dimensões de análise, cada uma delas subdividida em subcate-

152 gorias: Práticas de cuidado e educação dos adultos em relação às crianças e das crianças entre si (Formas de Comunicação e Linguagem; Espaços, tempos e materiais) e Traços das culturas infantis (Interatividade: amizades, aproximações e conflitos; Imaginário e ludicidade entre pares e sozinhos). No que diz respeito à análise dos dados, novamente citamos Denzin, pois a interpretação dos dados confrontou-nos com impressões, vídeos e notas de campo, certamente um desafio de "fazer sentido do que foi aprendido", ou a arte de produzir sentidos e significados a partir das informações (DENZIN, 1978). Conforme previamente anunciado, o foco das análises está na interatividade entre bebês, compreendendo as aproximações, amizades e conflitos entre eles, o que discutiremos nas próximas seções.

\section{Relações de amizade, conflitos e suas resoluções entre bebês}

As aproximações, amizade e conflitos são interações envoltas em emoções, as quais são aprendidas e acrescidas de experiências entre bebês, entre bebês com outras crianças e com adultos. Quanto mais variadas e ricas as experiências, as interações com os pares tornam-se mais complexas, desde 
que adultos permitam que a interatividade aconteça, garantindo, por exemplo, que os bebês enxerguem uns aos outros quando estão nos carrinhos, cadeirinhas, mesas, entre outras mudanças espaciais que diminuam a intervenção dos adultos, no sentido de tutela das relações de amizade e conflitos, impedindo que estas avancem e se complexifiquem.

Pela análise dos dados, como também pelos Estudos da Criança, constatamos que bebês desenvolvem modos de interatividade que são diferentes das interações dos adultos, principalmente pelas culturas da infância. Trevisan (2016), ancorada em estudos de Montandon (1 996), Torres (2000) e Harris (1996), desenvolveu uma pesquisa sobre amizade e amor do ponto de vista de crianças entre seis e dez anos de idade. Embora a autora não tenha realizado investigação com bebês, nossa intenção é discutir, brevemente, sua abordagem sociológica das emoções, tendo em vista que a interatividade é construída social e culturalmente, não sendo apenas uma construção individual. Logo, a emoção é construída na aprendizagem e na interação com os outros, numa relação intersubjetiva entre a sociedade adulta e a "sociedade infantil" (RAYOU, 1999) e no contexto das culturas de pares (TREVISAN, 2016).

Conforme argumenta Trevisan (2016), os Estudos da Infância, especialmente pelas contribuições da Sociologia da Infância, procuram suprir as dicotomias entre objetivo/subjetivo, ação/estrutura, inspirados nos estudos de Weber, que definiu a ação social como constituída de significados subjetivos. Até então, a sociologia compreendia a ação humana como motivada apenas por competências racionais, sem contemplar as emoções (TREVISAN, 2016).

Em estudos sobre criança e emoção, Harris (1996) questiona como a criança consegue identificar diferentes emoções, por exemplo, como ela perceberá que alguém está triste, feliz, zangado, etc. Uma das respostas possíveis parece passar por dois eixos: por um lado, a capacidade de reconhecimento das emoções assume-se como uma capacidade geral do ser humano e, portanto, também da criança; por outro, a criança aprende a reconhecer emoções dependendo do contexto em que se insere e do conhecimento que adquire acerca delas através de outras pessoas (TREVISAN, 2016). A imaginação assume um papel importante para o entendimento das emoções e, segundo Harris (1996), sem a capacidade de imaginação, não poderíamos participar plenamente da vida humana. 
Deste modo, pelos estudos de Harris (1 996 apud TREVISAN, 2016), os bebês observam as emoções dos seus pares e adultos e reagem a elas, tendo as crianças mais velhas um conceito mais cognitivo sobre a emoção.

Esses estudos, certamente, contribuem para o trabalho pedagógico com bebês e destacamos ainda que Tristão (2004) constatou que, por meio da emoção, o bebê mobiliza o outro para atender às suas necessidades, lembrando que os bebês dependem do outro para sobreviver. Assim, a dependência não é apenas física, pois Tristão constatou que o canal da emoção garante a responsividade dos adultos que cuidam e educam bebês. Ela também observou, em sua pesquisa, que eram fomentadas no berçário brincadeiras e possibilidades que seriam improváveis se partíssemos da concepção de criança descrita pelos manuais de desenvolvimento infantil. Nesses manuais, os bebês são vistos como seres que não têm capacidade de simbolizar, de fantasiar, de se concentrar e se relacionar com o outro (TRISTÃO, 2004).

\section{Das aproximações e relações de amizade entre bebês}

Não pretendemos conceituar amizade e conflitos entre bebês, pois são formas de interação ambíguas e contraditórias. Desse modo, a amizade entre os bebês pode estar conectada com sentimentos de empatia, contudo não se trata apenas de sentimentos altruístas ou fraternos. Foi o que constatamos nas aproximações delineadas pela ajuda, exclusão, disputas, pedidos, gritos, choros, frustrações, satisfação com avanços dos amigos, além dos sentimentos de igualdade ou concordância. Essas aproximações eram, ao mesmo tempo, desafiadoras e questionadoras quanto aos papéis e ações estabelecidos nas relações entre pares.

Mailat (2004) aborda a amizade na infância de um ponto de vista filosófico e argumenta que ela é fruto de uma promessa de alteridade, pois o outro na amizade pode ser o companheiro ou o adversário. Portanto, ela relaciona a amizade com a liberdade. Os laços de amizade entre bebês são, muitas vezes, vistos com desconfiança entre adultos, pois há uma relação de diferença que nem sempre se submete à norma escolar, geralmente pautada pela evitação dos conflitos e ênfase em normas para a formação do ofício de aluno (SARMENTO, 2004). Entre amigos, as normas podem ser subvertidas e surgem mais interrogações sobre o que adultos estabelecem como regras ou formas aceitáveis de se relacionar, entre outras normatizações dos tempos, 
espaços e relações. Então, nada mais perigoso do que a amizade, que Maïlat (2004, p. 10) associa a "[...] navegação nas águas do interdito, sobre os traços de Dionísio e de Orfeu [...]", algo realmente difícil de prever e controlar.

A autora (2004) narra que, na filosofia antiga, uma vida sem amigos não valia a pena ser vivida. A ajuda dos amigos era uma preciosa potencialidade para suportar o infortúnio ou os golpes duros da vida. Para os guerreiros de Atenas, o amigo continuava amigo, ainda estando morto. Se ele tombava no campo de batalha e seu cadáver estava entre as mãos dos inimigos, era preciso salvar o amigo, pois, deixar seu cadáver sem sepultura, seria insuportável.

Por conseguinte, uma abordagem da amizade e dos conflitos entre bebês tratada apenas no âmbito do privado ou de uma disposição interna ou individual seria um contrassenso. Consideramos a relação com o coletivo, com o social e o político, abrangendo as formas que os bebês encontram para resistir às políticas de controle e regulação das suas vidas nas escolas infantis. Eles se procuram ou se ajudam mesmo em posições que não facilitam que se vejam frontalmente, buscam abrir portas e janelas em direção à rua e à natureza, se escondem e procuram lugares abrigados do controle, percorrem espaços que adultos não conseguem atingir com seus corpos, enxergam coisas minúsculas e experimentam tudo com o corpo inteiro, buscam objetos fora do seu alcance, criam formas próprias de comunicação entre pares e com adultos.

Os bebês, tanto na sala de referência como nos demais espaços da escola infantil, desenvolviam interações tangenciadas pelo jogo de aproximação e afastamento, um modo de brincar entre si e de explorar os espaços e tempos da escola infantil.

\section{'Aparece e Desaparece'}

Anaí olha para a janela da sala do berçário e uma colega está atrás da cortina. Anaí imediatamente vai até a cortina e a levanta para também se esconder. A colega dá alguns tapas em Anaí, indicando que não permite que ela continue ali. Porém, Anaí não revida, segue ali, descobre o rosto com a cortina e a outra menina para de bater. Anaí e a outra menina interagem, balançam a cortina, cobrem o rosto com ela, se olham. A outra menina se afasta e Anaí segue naquela interação com a cortina, a colocando em seu rosto e caminhando (BERÇÁRIO 1, 2014a). 


\section{'Brincando atrás do sofá'}

Izadora está atrás do sofá que fica perto da janela da sala que dá acesso a um dos pátios da escola. Carol também está atrás do sofá, em um cantinho, e lzadora a observa. Carol tenta passar entre o sofá e uma pilha de colchões encostados na parede. Izadora chega perto de Carol, que está de costas para ela, toca suas costas e parece desejar que a colega passe. Carol consegue passar atrás do sofá e lzadora faz o mesmo movimento. Mikael, outro bebê, também vai para trás do sofá e passa por trás do mesmo, assim como Carol e Izadora. Enquanto isso, um menino do berçário 2, que estava na sala brincando com o B 1, observa esta 'brincadeira' e também faz o mesmo movimento dos outros. Ao mesmo tempo em que ele vai para fazer a volta no sofá, Carol tenta fazer a rotação inversa à que tinha feito antes, assim, tenta passar primeiro, por onde saiv, mas fica de frente para o menino do B2, que quer passar também. Mikael e lzadora observam os dois (BERÇÁRIO 1, 2013c).

Corsaro (201 1) e Carpenter (2010) asseguram que as crianças sentem necessidade de se ocultar dos adultos. $\bigcirc$ segredo e o esconderijo, para Carpenter, estabelecem linhas de demarcação potentes e permitem separar o 156 que pertence ao mundo das crianças e o que pertence ao mundo dos adultos um forte indício de alteridade das culturas da infância, identificado por Sarmento (2004). No caso dos bebês, os resultados da pesquisa reafirmam a importância das brincadeiras de aparece e desaparece, bem como dos cantos, cabanas, caixas, dos espaços separados dos espaços dos adultos. Além disso, os cantos e espaços ocupados pelas crianças são diferentes em função do seu tamanho, da corporeidade, da forma como se movimentam. São outras formas de apropriação dos espaços, que não são definidas e modeladas pelos modos adultos de se movimentar.

Assim, as brincadeiras de aparece e desaparece com a cortina e o esconder-se atrás do sofá entre Anaí, Izadora, Carol e Mikael demonstram como é importante para os bebês, espaços separados dos adultos. Isso pode ser proposto na organização dos espaços/ambientes dos berçários, considerando que pensar, criar, modificar espaços é um ato pedagógico de suma importância nessa fase da vida.

Um outro dado a destacar é que as aproximações e amizade entre bebês costumavam variar e estes, comumente, não mantinham relações estáveis com dois ou três amigos. Como apontou Corsaro (201 1), em estudo realizado 
acerca da amizade entre crianças em idade pré-escolar, o desenvolvimento de conhecimento acerca da amizade está diretamente relacionado com as exigências contextuais e sociais do grupo de pares em que a criança se insere. Ele viu que as crianças começam a perceber que a interação com os seus pares é frágil e que a sua aceitação na participação do grupo nem sempre é fácil. De acordo com Trevisan, para superar essas dificuldades, as crianças utilizam uma estratégia que passa por manter diversos contatos estáveis com várias crianças, mais do que manter apenas duas ou três delas, tendo em vista que a amizade também é definida pela situação presente que experienciam (TREVISAN, 2016).

Constatamos que, dificilmente, as crianças mantinham continuidade e estabilidade na interatividade, tanto pelas razões já apresentadas, quanto por outras hipóteses que fomos construindo no processo de pesquisa. Uma delas diz respeito à variabilidade das entradas e saídas das crianças dos berçários, causada por fatores, como: mudanças de endereço ou de cidade entre familiares dos meios populares, bebês que faltavam alguns dias ou semanas devido a doenças ou invernos rigorosos com chuvas, além do preenchimento de vagas ao longo do ano, o que, normalmente, alterava as rotinas dos bebês e suas interações. Outra situação diz respeito à mobilidade corporal de alguns bebês que podiam circular entre os colegas restritos aos carrinhos ou sentados em almofadas.

No episódio que segue, as aproximações se estabelecem pelo compartilhamento de descobertas, pela solidariedade e satisfação. São conquistas que fortalecem os laços afetivos com os pares. Embora sejam situações muito rápidas, haja vista que outras podem suceder imediatamente com crianças diferentes, é incontestável que relações de amizade ocorram em meio à diversão ou sentimentos de pertencimento naquela dada situação. Mas indiscutivelmente, as aproximações e amizade entre os bebês estavam permeadas por "[...] rupturas, reencontros e reaproximações e em muitas situações também percebemos uma suspensão temporária da relação até que esta fosse retomada" (TREVISAN, 2016, p. 119).

\section{'Explorações com televisão'}

Mikael e Davi estão perto da televisão da sala do berçário. Mikael está na ponta dos pés e com o dedo indicador mexe nos botões da televisão, que está desligada. Davi se afasta, mas volta para perto de Mikael e da televisão. Mikael por um instante para de mexer 
e olha para a câmera, mas quando vira para a televisão e para Davi, ela liga, pois ele apertou o botão. Davi comemora, sorrindo e batendo palmas, olhando para a televisão. Nesse momento, um menino, que é do B2 e estava brincando na turma do B I, se aproxima devagar deles e da televisão. Davi dá uns pulinhos, como se vibrasse pelo amigo ter conseguido ligar a TV, e Mikael segue mexendo nos botões e olhando para a tela para ver o que acontece. Mikael consegue desligar a TV e Davi acompanha tudo e olha para o lado que está a professora, parecendo cuidar para ver se ela não está vendo o que o amigo está fazendo. Mikael liga e desliga a TV várias vezes. Davi olha para a TV, se mexe, balança as mãos, parecendo estar numa espécie de tensão, com medo que a professora veja e os repreenda e também como se comemorasse as ações de Mikael. Mikael vai virando seu corpo em círculo e olha para o lado da professora e depois para Davi e volta a mexer na TV. Nesse momento a professora se dá conta que Mikael está mexendo na TV e o repreende, chamando pelo seu nome de maneira firme. Ele se vira pra ela, sorri e abana como se dissesse 'eu não estou fazendo nada de errado' (BERÇÁRIO 1, $2013 d$ ).

No episódio a seguir, constatamos que o desejo de estar na rua, fora da sala de referência, em ambientes com terra, plantas, ao ar livre, mobilizava, frequentemente, os bebês. De modo igual, observamos ações de escalar as janelas para olhar o pátio ou de abrir a porta da sala de referência em direção ao corredor que dava acesso ao refeitório e ao pátio.

\section{'Tentativas de abrir o portão'}

Davi está sentado na motoca, sem se mexer. Mikael, que estava ao seu lado, se posiciona atrás dele e começa a empurrar a motoca; Davi ajuda com os pés e quando chega em frente a parede, para, olha para trás e fala "sai" para o Mikael, que já estava saindo. Davi, ainda em cima da motoca, vai até o portão de ferro, que está fechado e que dá acesso a outra parte do pátio da escola. Ele bate com a mão no portão, tentando abri-lo e depois toca no trinco mais abaixo, mas este também não abre. Mikael, que percebe a ação do colega, vai até o portão e o sacode na tentativa de abrir. Davi, com os pés, empurra a motoca contra o portão algumas vezes, mas este não abre. Mikael, agarrado ao portão, observa Davi (BERÇÁRIO1, 2013a).

Nos episódios Explorações com a televisão e Tentativas de abrir o portão, as aproximações também se constituem em torno de objetivos em comum, 
tentativas de ajuda e regozijos com as descobertas dos amigos. Tratam-se de conquistas partilhadas e que fortalecem os laços afetivos com os pares. De modo igual, observamos ações de escalar as janelas para olhar o pátio ou de abrir a porta da sala de referência em direção ao corredor que dava acesso ao refeitório e ao pátio.

Carpenter (2010, p. 51 ) escreve que as crianças são maravilhadas pelo mundo natural, se admiram e são capazes, segundo Blake, "[...] de vislumbrar todo um mundo em um grão de areia, um paraíso em uma flor selvagem, de ter o infinito na palma da mão e a eternidade no espaço de uma hora". Assim, elas são transportadas, desde cedo, por experiências baseadas na imaginação.

Outro dado que encontramos tanto nas aproximações e relações de amizade como nos conflitos, é que o brincar frequentemente atravessava a interatividade entre os bebês. Provavelmente seja por isso que as crianças, quando se encontram em praças, nos pátios das escolas, ou em parques, mesmo que não se conheçam, imediatamente, passam a brincar e partilhar coisas coletivamente, como catar objetos e elementos da natureza, emitir sons similares, ainda que não falem, em aproximações mais espontâneas, sem as pré-condições e exigências típicas dos adultos.

\section{Dos conflitos e suas resoluções entre bebês}

Na análise dos conflitos, nossa intenção não é separá-los das aproximações e relações de amizade, pois eles fazem parte das parcerias e aproximações entre amigos. Como demonstra Corsaro (201 1), conflitos e disputas são um modo de testar a amizade e permitem construir uma ordem social. Leconte (2004, p. 34), ao refletir sobre a amizade na infância, informa que o paradoxo é que a parceria se desenvolve conjuntamente com a rivalidade e a competição.

Percebemos que os mais fortes, os que caminharam mais cedo, tinham mais mobilidade corporal e já pronunciavam palavras ou frases circulavam mais em situações que fugiam da tutela dos adultos. Leconte também constata em seus estudos que

[...] os mais vigorosos impõem ao grupo a dupla lei da admiração e da imitação, tendo em vista que não há receita para constituir um 
grupo de amigos; a solução é frágil, sempre pronta a se desfazer ou a se desnaturalizar (LECONTE, 2004, p. 35).

Trevisan (2016) constatou que as crianças não se relacionam entre si da mesma forma e que o gênero exerce um papel na definição do tipo de amizades que estabelecem, assim como se distinguem claramente os grupos onde estão inseridas as crianças mais populares da sala. As meninas e os meninos tendem a desenvolver relações intragênero (meninas com meninas e meninos com meninos), mas a pesquisadora também observou diferentes brincadeiras e interesses permeados por relações intergênero.

A frequência nos agrupamentos intragênero e o estatuto da popularidade foram observados entre os bebês dos berçários I e II. Davi caminhou e falou mais cedo entre os colegas do grupo e seus deslocamentos na sala entre diferentes grupos era um facilitador para que ele ampliasse e diversificasse as relações. Ele costumava desencadear conflitos nas disputas por brinquedos e objetos e, geralmente, vencia alguns bebês. Sua popularidade parecia ser reconhecida entre seus pares e entre alguns adultos. Todavia, ele também era mais repreendido pelas professoras e auxiliares. Outrossim, em vários episódios, constatamos uma presença mais efetiva de agrupamentos entre bebês meninos e bebês meninas.

Corsaro (2011) expõe que, na produção das rotinas lúdicas, as crianças têm como objetivo a amizade, o compartilhamento e a participação social, assim como o controle sobre o mundo adulto. Isso significa que elas partilham com o grupo de pares conflitos e angústias, gerados pela sua imersão na vida adulta, um jogo com regras criadas e seguidas pelas crianças.

'Disputa pela colher de bater merengue'

Natan vai até a parede da bancada onde são feitas as trocas de fraldas das crianças e bate com a colher na parede. Izadora brinca com uma motoca e, quando vê Natan do seu lado com a colher, larga a motoca e tenta retirar a colher da sua mão. Mas ele se afasta, impedindo-a. Izadora retoma a motoca e Natan segue para outro ponto da sala com a colher (BERĆÁRIO 1, 2013e).

\section{'A Disputa pela Motoca'}

Davi e José estão em um canto, segurando ao mesmo tempo uma motoca. José puxa o brinquedo e balbucia reclamando que o colega não solta o brinquedo. Davi olha para outro colega - Mikael -, mas com a mão no brinquedo. Mikael olha para o brinquedo, 
mas não participa da ação, apenas caminha até um portão de ferro que dá para o pátio. Davi puxa um pouco mais forte a motoca e José, segurando o brinquedo, olha para o colega e balbucia com um tom de voz alto e de reclamação. Davi se mantém com a mesma expressão facial, sério. Os dois não soltam a motoca, olham por um momento para frente, onde estão as professoras e alguns colegas, e voltam o olhar novamente para o brinquedo. Davi vai andando para trás, puxando o brinquedo em sua direção e José tenta tirar a mão de Davi da motoca, mas não consegue. José segue reclamando e olha novamente para a direção das professoras, como se estivesse pedindo ajuda. Neste momento Mikael, que estava no portão, se aproxima e pega a camiseta do José. Depois solta, mas a disputa pelo brinquedo entre os outros dois colegas segue. Mikael agora olha para a motoca, observa por alguns segundos a cena e vai novamente para o portão. José e Davi puxam o brinquedo, cada um para um lado, mas José é o único que grita e reclama forte. Davi está sempre com a mesma expressão, apenas se mantém firme na posição de disputa. José, mais uma vez, tenta tirar as mãos de Davi do brinquedo, mas não consegue. $\bigcirc$ balbucio de José vira um choro, ele olha para quem está filmando e volta a olhar para o brinquedo. Davi também olha, mas não fala nada. Cada um puxa para um lado, José sempre choramingando enquanto tenta pegar o brinquedo e Davi calado. Mikael se aproxima dos colegas e olha para cada um. Primeiro olha para José, depois para Davi e por último para o objeto (BERÇÁRIO 1, 2013 b).

Segundo Carpenter (2010), um traço universal, nas culturas infantis, é o sentido da justiça, nem sempre coerente com as crenças e valores adultos. As crianças são capazes de resolver conflitos, embora saibam que, na escola infantil, estes geralmente são suspensos pelos adultos, quando elas choram, disputam algum brinquedo ou usam a força bruta nas disputas. Muitas vezes os bebês olhavam e esperavam a reação dos adultos, como na disputa por uma motoca ou por outros objetos. No entanto, em outras situações de conflitos, surgiam resoluções inesperadas, como abandonar um brinquedo, um objeto ou um grupo de amigos, uma vez que, imediatamente, outros interesses eram despertados.

Nessas situações, também, constatamos ampla atividade e movimento, o que talvez explique as mudanças inesperadas em momentos que nós adultos muitas vezes qualificamos como tensos e perigosos, na medida em que o uso da força bruta pode machucar alguns colegas. Tais descobertas 
Interatividade nas culturas da infância: aproximações, amizade e conflitos entre bebês

geralmente ocorrem via atividade lúdica, com exploração, manipulação e domínio do ambiente. Conforme descreve Carpenter:

As crianças são motivadas a continuar a exploração do mundo pela curiosidade, pelo desejo de saber e compreender, resultado do desejo de experiência e de confrontações dionisíacas frente aos limites impostos pelos ambientes sociais, naturais, assim como os limites de seu próprio corpo. Tais explorações geralmente ocorrem via atividade lúdica, com exploração, manipulação e domínio do ambiente (CARPENTER, 2010, p. 50).

Vejamos dois episódios nos quais essa intensidade de explorações lúdicas pode ser constatada, não esquecendo que as explorações, em alguns momentos, atingem um grau de tensionamento gerado pelas disputas e conflitos:

\section{'Entrando na caixa'}

Carol está dentro de uma caixa com rodinhas que tem no refeitório. A caixa é usada para guardar alguns materiais como potes, caixas, brinquedos. Ela está sentada dentro da caixa e brinca com dois potes. As professoras que estão por perto comentam: 'olha lá, Carolzinha, pode entrar'. Carol olha em direção à professora que disse isso e Davi se aproxima da caixa, se agacha e pega um dos potes da caixa. Ele se afasta e ela observa, mas não resiste. Nesse momento, Natan se aproxima da caixa, se segura com as mãos para tentar entrar, mas Carol grita com ele e bate em sua mão para que ele não entre. Ele vai para outro canto e tenta de novo, mas Carol olha para ele e tira suas mãos de novo da caixa. Nesse instante, uma das professoras chama pelo nome de Natan e diz 'Natan, ela não quer!'. Davi se aproxima de novo, se agacha e tenta entrar pelo meio da caixa, pois esta tem abertura entre a parte de cima e a de baixo. Davi tenta colocar a cabeça primeiro, mas desiste em seguida. Carol olha para ele, enquanto Natan está com uma das pernas levantadas, tentando subir na caixa. Uma das professoras, percebendo que mais crianças desejam entrar na caixa, pega Natan, o afasta para o lado e pede que ele espere. Ela arreda a caixa com Carol dentro, pois a caixa estava encostada na parede e depois começa a tirar objetos para dar mais espaço para os outros. Assim que ela termina de arredar a caixa, Davi se aproxima e já tenta subir, sem esperar ajuda e que ela tire os objetos de dentro. Natan também procura um lado da caixa para tentar subir. Ele se segura, põe um pé na caixa, enquanto a professora 
pega Davi e o coloca na caixa. Natan vai para outro lado da caixa e novamente faz a tentativa de entrar sozinho. Carol, que estava brincando com os potes dentro da caixa, olha para Natan e o empurra dando um gritinho para que ele não suba. A professora chega, pega Natan, vai para outro lado e o põe dentro da caixa. Carol para de brincar nos potes, faz um movimento parecendo que irá se levantar, mas apenas se vira em direção a Davi e Natan, que estão sentados na caixa (BERÇÁRIO 1, 2014).

No episódio Entrando na Caixa, percebemos como a sensibilidade da professora contribuiu para que o grupo pudesse interagir com a caixa, ampliando os movimentos corporais de exploração das potencialidades que uma caixa grande pode oportunizar, além das interações entre pares. Provavelmente, a professora entendeu que a imaginação dos bebês pode ampliar as experiências com a caixa, o que desencadeou uma infinidade de possibilidades entre o grupo.

Os bebês, frequentemente, viviam experiências de negociação nas disputas, permeadas por emoções como estranhamento, conflitos e breves acordos, cuja duração poderia ser rompida a qualquer instante. Daí, a urgência de estudos sobre a problemática, pois, geralmente, professoras utilizam normas para resolução de conflitos que não fazem parte das manifestações de interatividade dos bebês. Quando não há riscos para os bebês, adultos podem observar tais situações e aprender sobre as competências sociais e a complexidade na construção dessas relações que os bebês vão aprendendo entre si, assim como a originalidade com que resolvem os conflitos.

\section{Para concluir...}

Pelos estudos até aqui realizados, constatamos que a amizade entre os bebês pode estar conectada com sentimentos de empatia, contudo não se trata apenas de estabelecer parcerias e compartilhar experiências. Foi o que percebemos nas aproximações delineadas pela ajuda, exclusão, disputas, pedidos, gritos, choros, frustrações, regozijos com avanços dos amigos, cobranças, além dos sentimentos de igualdade ou concordância. Consoante com Mailat (2004, p. 12), nós almejamos contribuir com reflexões sobre aproximações, amizades e conflitos entre bebês, uma vez que esta temática tem sido "[...] coberta de suspeitas e estigmatizada [...]". 
A autora (MAÏLAT, 2004) aborda a amizade na infância de um ponto de vista filosófico e argumenta que ela é fruto de uma promessa de alteridade. Os laços de amizade entre bebês são, muitas vezes, vistos com desconfiança entre os adultos, pois há uma marca de diferença, que nem sempre se submete à norma escolar, geralmente pautada na evitação dos conflitos. Entre amigos, as normas podem ser subvertidas e surgem mais interrogações sobre o que os adultos estabelecem como regras, formas de se relacionar, entre outras normatizações dos tempos, espaços e relações.

$\bigcirc$ excesso de atividades rotineira se o desejo de manter os bebês sempre ocupados podem minimizar as aproximações e as relações de amizade que sempre desorganizam o que está feito, pronto, estruturado. Constatamos que os bebês, embora dependentes das professoras e auxiliares, são potentes para interagir entre si, são capazes de criar diferentes possibilidades de interatividade, de modificar espaços, tempos, materiais e de criar formas originais para estabelecer laços de amizade e resolver conflitos e disputas entre si. Pensamos que refletir sobre a interatividade, decorrente da análise dos dados de uma pesquisa qualitativa, também poderá contribuir para a formação inicial e continuada de professoras de educação infantil.

\section{Notas}

1 Manuel Sarmento compreende as culturas da infância como modos sistematizados de significação do mundo e de ação intencional, realizados pelas crianças, que são distintos dos modos adultos de significação e de ação no mundo (SARMENTO, 2004).

2 Segundo Gottlieb, a localização do segundo aniversário como fim da idade de bebê de colo é baseada em um pressuposto cultural de que os estágios da vida têm de ser definidos pela referência a uma duração de tempo absoluta e não a mudanças de atividades. Se o término da idade de bebê de colo é variável entre culturas, o mesmo é verdadeiro sobre o seu início (GOTTLIEB, 2013 , p. 91-921.

3 James, Jenks e Prout (1998) identificam dois períodos dos estudos da infância. No da criança pré-sociológica encontram-se visões sobre a infância e crianças do senso-comum, da filosofia clássica, da psicologia do desenvolvimento e da psicanálise. No período da criança sociológica, conceitos centrais das teorias da Sociologia da Infância como as culturas da infância são complexificados (SARMENTO, 2007). Nossa opção é pela perspectiva da criança sociológica.

4 Neste artigo, somente os dados da turma do berçário serão tema de análise e os nomes dos bebês são fictícios.

5 Tal como o autor, não estamos separando a teoria da metodologia. 


\section{Referências}

ARLEO, Andy; DELALANDE, Julie. Cultures enfantines. Universalité et diversité. Rennes: Presses Universitaires de Rennes, 2010.

BERÇARIO 1. Transcrição de vídeo. Pelotas (Rio Grande do Sul), 19 nov. 2013.

BERÇARIO 1. Transcrição de vídeo. Pelotas (Rio Grande do Sul), 19 nov. 2013 a.

BERÇARIO 1. Transcrição de vídeo. Pelotas (Rio Grande do Sul), 19 nov. 2013 b.

BERÇARIO 1. Transcrição de vídeo. Pelotas (Rio Grande do Sul), 17 dez. $2013 c$.

BERÇARIO 1. Transcrição de vídeo. Pelotas (Rio Grande do Sul), 17 dez. 2013 d.

BERÇARIO 1. Transcrição de vídeo. Pelotas (Rio Grande do Sul), 25 nov. 2013 e.

BERÇARIO 1. Transcrição de vídeo. Pelotas (Rio Grande do Sul), 3 abr. 2014.

BERÇARIO 1. Transcrição de vídeo. Pelotas (Rio Grande do Sul), 5 jun. $2014 a$.

BLAKE William. Auguries of innocence. Poème Rédigé entre 1800 et 1803, publié pour la première fois en 1863.

BROUGÈRE, Gilles. Culture de masse et culture enfantine. In: ARLEO, Andy; DELALANDE, Julie. Cultures enfantines. Universalité et diversité. Rennes: Presses Universitaires de Rennes, 2010.

BROUGÈRE, Gilles; ULMANN, Anne-lise. Aprender pela vida cotidiana. Campinas: Autores Associados, 2012.

CARPENTER, Carole. Les universaux de la culture enfantine. In: ARLEO, Andy; DELALANDE, Julie. Cultures enfantines. Universalité et diversité. Rennes: Presses Universitaires de Rennes, 2010.

$\mathrm{COHN}$, Clarice. Antropologia da criança. Rio de Janeiro: Zahar, 2005.

CORSARO, Willian. Reproduction interprétative et culture enfantine. Universalité et diversité de l'expression. In: ARLEO, Andy; DELALANDE, Julie. Cultures enfantines. Universalité et diversité. Rennes: Presses Universitaires de Rennes, 2010.

CORSARO, Willian Arnold. Sociologia da infância. Porto Alegre: Artmed, 2011. 
DENZIN, Norman Kent. The research act: a theoretical introduction to sociological methods. 2. ed. New York: Mc Graw-Hill, 1978.

DOLTO, Francoise. La cause des enfants. Paris: Éditions Robert Laffont, 1985.

FERREIRA, Manuela; NUNES, Angela. Estudos da infância, antropologia e etnografia: potencialidades, limites e desafios. Linhas Críticas, Brasília, v. 41 , n. 20, p. 103-123, jan./abr. 2014.

FONSAGRIVE, Anne. Premières amitiés. ERES. La lettre de l'enfance et de l'adolescence, Paris, v. 55, n. 1, p. 67-72, 2004.

GOTTLIEB, Alma. Para onde foram os bebês? Em busca de uma Antropologia de bebês le de seus cuidadores). Revista de Psicologia da USP, São Paulo, v. 20, n. 3, p. 31 3-336, jul./dez. 2009. Disponível em: <http://www.scielo.br/scielo.php?script=sci_arttext\&pi $d=S 0103-5642009000300002>$. Acesso em: 15. out. 2015.

GOTTLIEB, Alma. Tudo começa na outra vida: a cultura dos recém nascidos na África. São Paulo: Fap-Unifesp Editora, 2013.

GRAUE, Elizabeth; WALSH, Daniel. Investigação etnográfica com crianças: teorias, métodos e ética. Lisboa: Fundação Calouste Gulbenkian, 2003.

HARRIS, Paul. Criança e emoção. O desenvolvimento da compreensão psicológica. São Paulo: Martins Fontes, 1996.

JAMES, Allison; JENKS, Chris; PROUT, Alan. Theorizing childhood. Cambridge: Polity Press, 1998.

LECONTE, Xavier. Compter avec les autres. ERES. La lettre de l'enfance et de l'adolescence, Paris, n. 1, v. 55, p. $31-36,2004$.

MÄ̈lAT, Maria L'ami. Absence et préexcellence lettre à Tristan. ERES. La lettre de l'enfance et de l'adolescence, Paris, n. 1. v. 55, 9-16, 2004.

MONTANDON, Cléopâtre. Processus de socialisation et vécu emotionnel des enfants. Revue Française de Sociologie, n. 2, v. 37, avril, p. 263-282, 1996.

NEYRAND, Gerard. L'enfant, la mère et la question du pére: un bilan critique de l'évolution des saviors sur la petite enfance. Paris: Presses Universitaires de France, 2000.

RAYOU, Patrick. La grande école. Approche sociologique des compétences enfantines Paris, PUF, 1999. 
ROGOFF, Barbara. A natureza cultural do desenvolvimento humano. Porto Alegre: Artmed, 2005.

SARMENTO, Manuel Jacinto. As culturas da infância nas encruzilhadas da segunda modernidade. In: SARMENTO, Manuel Jacinto; CERISARA, Ana. Beatriz. Crianças e miúdos: perspectivas sócio pedagógicas da infância e educação. Porło: ASA, 2004.

SARMENTO, Manuel Jacinto. Visibilidade social e estudo da infância. In: VASCONCELLOS, Vera. Maria. Ramos; SARMENTO, Manuel. Jacinto (Org.). Infância (in)visível. Araraquara: Junqueira \& Marin, 2007.

SARMENTO, Manuel Jacinto. A reinvenção do ofício de criança e aluno. Atos de Pesquisa em Educação - FRU, Blumenau, v. 6, p. 581 1-602, set./dez. 2011.

SARMENTO, Manuel Jacinto. A sociologia da infância e a sociedade contemporânea. In: ENS, Romilda. Teodora; GARANHANI, Marynelma. Camargo. A sociologia da infância e a formação de professores. Curitiba: Champagnat, 2013.

TORRES, Anália Cardoso. Amor e sociologia: da estranheza ao reencontro. In: CONGRESSO PORTUGUÊS DE SOCIOLOGIA, 4 - SOCIEDADE PORTUGUESA: PASSADOS RECENTES, FUTUROS PRÓXIMOS; 2000, Coimbra. Actas... Faculdade de Economia da Universidade de Coimbra: 2000.

TREVISAN, Gabriela de Pina. "A amizade é a melhor coisa do mundo apesar do amor" - afectos e amores entre crianças - a construção de sentimentos na interacção de pares. 2006, 534f. Dissertação (Mestrado em Sociologia da Infância) - Instituto de Estudos da Criança, Universidade do Minho, Braga.

Amor e afectos entre crianças. A construção social de sentimentos na interacção entre pares. In: DORNELLES, Leni Vieira (Org.). Produzindo pedagogias interculturais na infância. Petrópolis: Vozes, 2007.

TRISTÃO, Fernanda Carolina Dias. Ser professora de bebê: um estudo de caso numa creche conveniada. 2004. 206f. Dissertação (Mestrado em Educação) - Programa de PósGraduação em Educação, Universidade Federal de Santa Catarina, Florianópolis, 2004.

Profa. Dra. Ana Cristina Coll Delgado Programa de Pós-Graduação em Educação Faculdade de Educação 
Universidade Federal de Pelotas Grupo de Pesquisa ClC - Crianças, Infâncias e Culturas E-mail | anacoll@vol.com.br

Prof. Dr. Rogério Costa Würdig Universidade Federal de Pelotas Faculdade de Educação Departamento de Ensino Grupo de Pesquisa ClC: Crianças, infâncias e culturas E-mail | rocwurdig@gmail.com Profa. Dra. Patrícia Pereira Cava Universidade Federal de Pelotas Faculdade de Educação

Departamento de Fundamentos da Educação Grupo de Pesquisa ClC: Crianças, infâncias e culturas E-mail | pcava@via-rs.net Recebido 27 jul. 2016 Aceito 7 fev. 2017 